\title{
CAMBRIDGE
}

\section{Schur Algebras and Representation Theory}

\section{S. MARTIN}

Dr Martin covers the basic ideas of classical Schur algebras and their quantum analogues. He also takes the opportunity to investigate the relationship between Schur algebras and other algebraic structures. This book is the only comprehensive and up-to-date treatment of Schur algebras and their quantum analogues. 630.00 net HB $0521415918 \quad 248$ pp. 1994 Cambridge Tracts in Mathematics 112

\section{Now in paperback}

\section{The Banach-Tarski Paradox}

\section{STAN WAGON}

Asserting that a solid ball may be taken apart into many pieces that can be rearranged to form a ball twice as large as the original, the BanachTarski paradox is examined in relationship to measure and group theory, geometry and logic.

'... this beautiful book is written with care and is certainly worth reading.'

\section{Mathematical Reviews}

'... a readable and stimulating book.'

E15.95 net PB 0521457041253 pp. 1993

\section{American Scientist}

\section{Now in paperback}

\section{Designs and their Codes}

\section{E. F. ASSMUS JR. and J. D. KEY}

This is a self-contained and up-to-date account of the applications of algebraic coding theory to the study of combinatorial designs. Whilst the book is aimed at mathematicians working in either coding theory or combinatorics, it is designed to be used by non-specialists and so is of value to graduate students or computer scientists working in those areas.

f17.95 net PB $0521458390 \quad 362$ pp. 1994 Cambridge Tracts in Mathematics 103

\section{Now in paperback \\ Numbers and Functions}

Steps into Analysis

\section{R. P. BURN}

The novel approach to rigorous analysis offered here is designed to enable students to grow in confidence and skill and thus overcome their traditional difficulties. Teachers in sixth forms will find that the beginning questions in every chapter provide ways of preparing those at school for university mathematics. Lecturers in universities will be challenged to rethink their conventions about the best way to introduce the central ideas of analysis to undergraduates. f 14.95 net PB $0521457734 \quad 352$ pp. 1993

\section{Now in paperback \\ Local Representation Theory}

Modular Representations as an Introduction to the Local Representation Theory of Finite Groups

\section{J. L. ALPERIN}

'... a beautifully written book. Anyone wishing to learn the fundamental facts of Brauer's theory of blocks cannot do better than to begin his study with this text.'

Bulletin of the London Mathematical Society

f14.95 net PB $052144926 \times 192$ pp. 1993

Cambridge Studies in Advanced Mathematics 11

\section{Computational Algebraic Geometry and Commutative Algebra}

\section{Cortona 1991}

Edited by D. EISENBUD and L. ROBBIANO Includes the most interesting trends and developments in the field, as well as an introduction to the theory of Gröbner bases and their use in computation. Of interest to mathematicians, and to computer scientists interested in symbolic computation. f29.95 net HB $0521442184 \quad 308$ pp. 1993 Symposia Mathematica 34 


\section{Now in paperback}

\section{Finite Group Theory}

\section{ASCHBACHER}

The foundations of the theory of finite groups are developed in this book. Unifying themes include the Classification Theorem and the classical linear groups. Lie theory appears in chapters on Coxeter groups, root systems, buildings and Tits systems. There is a new proof of the Solvable Signalizer Functor theorem and a brief outline of the proof of the Classification Theorem itself.

f16.95 net PB 0521458269288 pp. 1994 Cambridge Studies in Advanced Mathematics 10

\section{Now in paperback}

\section{Some Random Series of Functions}

\section{Second Edition}

J-P. KAHANE

'Kahane's book is more like a ramble through fine countryside. At every mile one is rewarded with a singing waterfall or an old farmhouse, and at virtually every step with a new wayside flower.' Proceedings of the Edinburgh Mathemetical Society f19.95 net PB $0521456029 \quad 316$ pp. 1993 Cambridge Studies in Advanced Mathematics 5

\section{Elementary Probability}

\section{STIRZAKER}

Elementary Probability provides a simple introduction to the theory of probability. This text contains numerous worked examples and exercises necessary for problem solving, as well as demonstrates the concepts involved. The topics covered illustrate the range and power of probability, and include conditional probability, independence, random variables, generating functions, and an introduction to Markov chains.

f45.00 net HB $0521420288 \quad 416$ pp. 1994 $£ 15.95$ net PB 0521421837

\section{ORDER FORM}

To order please send this form to Tom Peacock at the address below, 'phone 0223325970 or fax 0223315052 .

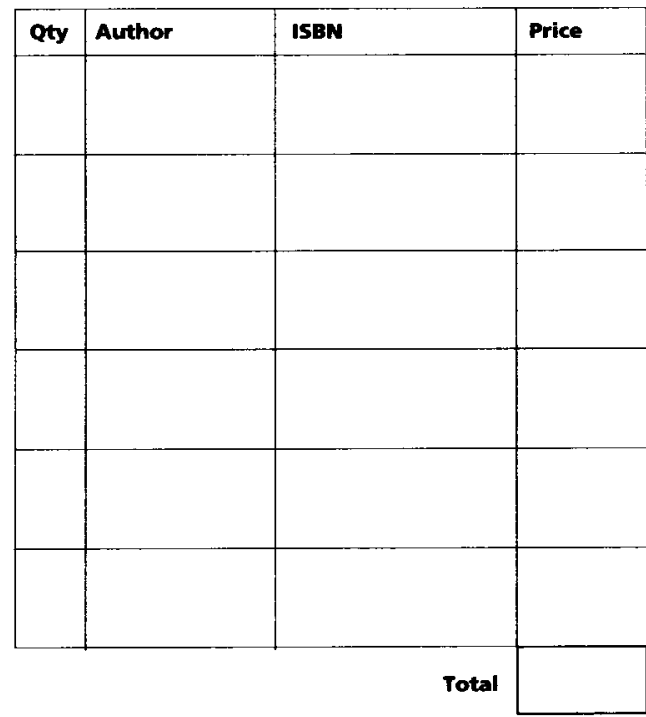

I enclose a sterling cheque/eurocheque (payable to Cambridge University Press)

$\square$ Please debit my credit card (Access/Mastercard/ VISA/Amex)* * Please delete as applicable

Card no.

Expiry Date

Signature

Name of cardholder

Address

\section{CAMBRIDGE} UNIVERSITY PRESS

FREEPOST, The Edinburgh Building,

Shaftesbury Rd., Cambridge CB2 IBR

E-mail: SCIENCE@CUP.CAM.AC.UK 


\section{INSTRUCTIONS TO AUTHORS}

\section{Submission of typescripts}

Two copies of the manuscript should be submitted to one of the four Executive Editors (addresses on outside front cover). Papers may also be submitted electronically to those Executive Editors with electronic mail addresses. The editor will acknowledge receipt of the manuscripts. It is important that authors inform the editor of any changes of address whilst their paper is under consideration.

\section{Typescript}

Papers should be typed, double-spaced, on one side only and with generous margins. The pages must be numbered.

The first page should give the title, the author's name and institution, and a short abstract intelligible to mathematicians.

The title, while brief, must be informative (e.g. $A$ new proof of the ergodic theorem, whereas Some applications of a theorem of Birkhoff would be useless).

\section{Notation}

It is important that mathematicians expressions are clear to a printer (who is not a mathematician). For instance, $n_{k}(n$ sub $k$ ) is common usage, but avoid if possible using $c$ sub $n$ sub $k$. Fractions are generally best expressed by a solidus. Complicated exponents like

$$
\exp \left\{z^{2} \sin \theta /\left(1+y^{2}\right)\right\}
$$

should be shown in this and no other way.

In the typescript, italics, small capitals and capitals are specified by single, double and triple underlining. Bold-faced types is shown by wavy underlining.

It helps if displayed equations or statements which will be quoted later are numbered in order on the right of their line. They can then be referred to by, for example, 'from (7)'.

The author must enable the printer (if necessary by pencilled notes in the margin) to distinguish between similar symbols such as $o, O, 0, \mathrm{O}, 0 ; x$, $\mathrm{X}, \times ; \phi, \Phi, \varnothing ; 1,1 ; \varepsilon, \epsilon ; \kappa, k$.

There is no need to underline Greek or script letters provided these are clearly typed. Any special symbols should be explained on a separate sheet of directions for the printer.

If an author wishes to mark the end of the proof of a theorem, the sign $\square$ may be used.

Footnotes should be avoided.

\section{Diagrams}

Figures and drawings should be on separate sheets in black ink. Photocopies are acceptable only if they are as clear as the originals. Symbols, legends and captions should be given on a transparent overlay. Each text figure must be numbered as Figure 1, Figure $2, \ldots$ and its intended position clearly indicated in the typescript. The author's name in pencil must be on all separate sheets of diagrams.

A figure is expensive to reproduce and should be included only when the subject matter demands it, or when it greatly clarifies the exposition.

The publisher recognizes that some authors do not have the facilities for producing drawings of a sufficiently high standard to be reproduced directly and is therefore willing to have such diagrams redrawn, provided that they are clear.

\section{Tables}

Tables should be numbered (above the table) and set out on separate sheets. Indicate the position of each in the text as for figures.

\section{References}

References should be collected at the end of the paper numbered in alphabetical order of the author's names. A reference to a book should give the title, in italics, and then in roman type the publisher's name and the place and year of publication;

[4] N. Dunford \& J. T. Schwartz Linear Operators Part I. Wiley: New York, 1958.

A reference to a paper should give in italics the title of the periodical, the number of the volume and year, and the beginning and end pages of the paper. Titles should be abbreviated as in Mathematical Reviews:

[6] J. E. Littlewood. The 'pits effect' for functions in the unit circle. J. Analyse Math. 23 (1970), 236-268.

\section{Proofs}

Authors receive one set of proofs for correction. If excessive alterations to the original manuscript are requested after the paper has been typeset, the author will be charged the cost of resetting. For papers with more than one author the proofs are sent to the first named author unless the editor receives other instructions. It is important that proofs are corrected and returned promptly.

\section{Reprints}

There are 100 reprints, free of charge, for each paper. For papers with several authors these reprints are divided between the authors. There are no page charges. 


\section{Ergodic theory and dynamical systems}

VOLUME 15 PART 2 APRIL 1995

\section{CONTENTS}

Adams $S$. Some new rigidity results for stable orbit equivalance

Alsedà $L l$. and $Y_{e} X$. No division and the set of periods for tree maps

Baldwin S. and Llibre J. Periods of maps on trees with all branching points fixed

Barbot $T$. Caractérisation des flots d'Anosov en dimension 3 par leurs feuilletages faibles

Buescu J. and Stewart I. Liapunov stability and adding machines

Díaz L. J. Robust nonhyperbolic dynamics and heterodimensional cycles

Jiang M., Pesin Ya $B$. and de la Llave $R$. On the integrability of intermediate distributions for Anosov diffeomorphisms

Lawrence D. A and Thomas E.S. A note on transitive flows

Qian N. Anosov automorphisms for nilmanifolds and rigidity of group actions

Starkov A. Minimal sets of homogeneous flows

Zeghib A. Ensembles invariants des flots géodésiques des variétés localement symétriques 